\title{
First time mothers' expectations and experiences of postnatal care in England: a longitudinal qualitative descriptive study
}

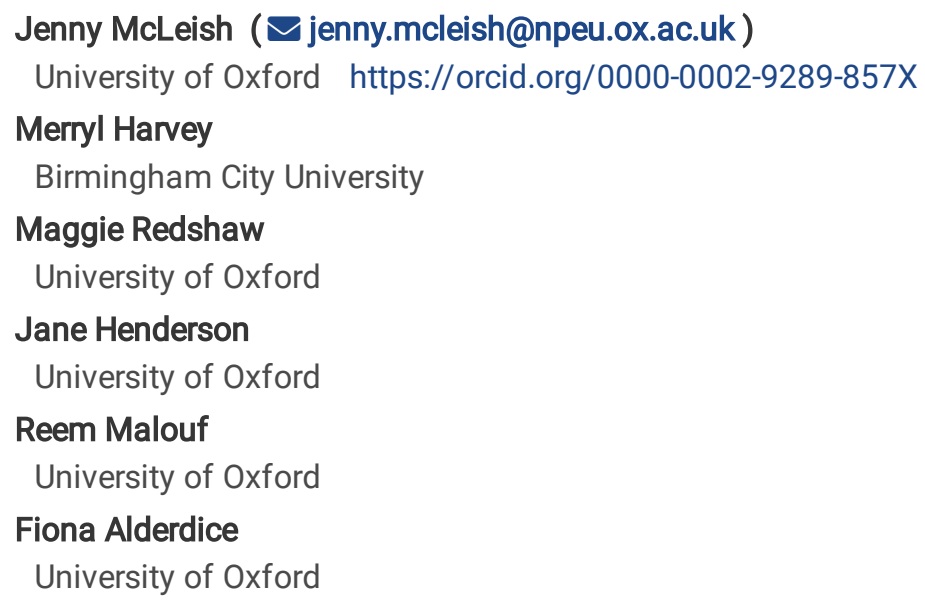

Research article

Keywords: Postnatal care, expectations, experiences, first time mothers, trajectory analysis, longitudinal

Posted Date: September 16th, 2019

DOI: https://doi.org/10.21203/rs.2.14438/v1

License: @ (1) This work is licensed under a Creative Commons Attribution 4.0 International License. Read Full License 


\section{Abstract}

Background: Effective postnatal care can support a safe and confident transition to parenthood, but it is the aspect of maternity care with which women in England are least satisfied. Little is known about first time mothers' expectations of postnatal care in hospitals, in birth centres and in the community, or how these expectations relate to their subsequent experiences and appraisal of care.

Methods: A longitudinal qualitative descriptive study, based on semi-structured, in-depth interviews with first time mothers in England. Each mother took part in two interviews: the first in her third trimester of pregnancy, and the second when her baby was 2-3 months old. Interview transcripts were analysed using trajectory analysis to identify thematic patterns in the relationships between postnatal care expectations, needs, experiences and confidence. Individual cases were chosen to illustrate each trajectory and the variation within trajectories.

Results: 32 women took part. Expectations of postnatal care did not shape their appraisal of care as actually experienced. Instead the main influence on satisfaction with care and self-described parental confidence was the extent to which their actual postnatal needs for support were met. Five trajectories were identified: (1) 'Low needs, low support, confident', (2) 'High needs, high support, confident', (3) 'High needs, low support, not confident', (4) 'High needs, high support, additional risk factors, not confident', (5) 'High needs, low support, additional protective factors, confident'.

Conclusions: Longitudinal qualitative research using trajectory analysis is a useful and feasible method of exploring expectations and subsequent experiences in the perinatal period. First time mothers' satisfaction with postnatal care and their confidence as new mothers were primarily influenced not by the extent to which their expectations were met, but the varied extent to which their postnatal needs were met. Rapid and responsive assessment of needs both antenatally and postnatally, and appropriate adjustment of care, is key in supporting women effectively at this time. Providing tailored information on postnatal care, self-care and transition to parenthood during pregnancy may facilitate improvements in women's experiences of care after birth in the hospital and community.

\section{Background}

Postnatal care has an important role in enabling a safe and successful transition to parenthood $(1,2)$. It is, however, the aspect of maternity care with which women in England are least satisfied (3). The Chief Medical Officer has criticised the current model of postnatal care as not fit for purpose (4), and the Royal College of Midwives and National Maternity Review have reported that postnatal care was under-resourced and not meeting women's needs $(1,5)$.

In surveys and qualitative studies, some women have reported negative experiences of the physical environment of postnatal wards, staff attitudes and communication, staff having insufficient time to offer meaningful support, lack of information about baby care, and insufficient or ineffective support for infant feeding $(3,6-10)$. The consequences of inadequatepostnatal care may be especially problematic for first time mothers, who need to develop parental confidence and skills (11-13). Timely information and affirmational support from professionals offered as part of postnatal care can help new mothers to develop this confidence $(14,15)$, which is inversely associated with stress, anxiety and postnatal depression (11).

Little is known about pregnant women's expectations of postnatal care. It has been suggested that some of the dissatisfaction women express in relation to their postnatal care may be attributable to the mismatch between their expectations and their experiences, and that this mismatch may be particularly acute for women from Black and ethnic minority communities $(9,16-18)$. The role played by expectations in patient satisfaction has been much debated, with some models proposing that expectations are an important component in satisfaction, or dissatisfaction where there is discrepancy $(19,20)$, while others argue that the significance of met or unmet expectations is eclipsed by other factors such as appraisal of actual experiences $(21,22)$.

Expectations are not a single concept, but can be divided into four different constructs (22): ideal (wants, hopes, preferences), predicted (real, anticipated outcomes), normative (what ought to happen) and unformed (where the person does not have any expectations). Studies of expectations and experiences of postnatal care have not always distinguished clearly between these different forms of expectations, nor between the expectations of first time mothers and those with previous experience of postnatal care, who may have different needs $(23,24)$. A small number of studies have investigated pregnant women's ideal expectations for postnatal care, with limited information about real expectations $(8,23,24)$. Other studies have asked women about their real postnatal care expectations retrospectively $(16,17,23,25)$. This is not necessarily a reliable way of exploring expectations, because after an event people may adjust or misremember their expectations in the light of outcomes or current circumstances $(22,26)$. Alternatively 
ideal or normative expectations have been inferred by researchers from women's answers to retrospective questions about postnatal experiences $(6,9,16,18,27,28)$.

This paper aims explores what first time mothers expected during pregnancy from their postnatal care, what they actually experienced, the influence of their predicted expectations on their appraisal of postnatal care, and the extent to which it affected their parental confidence. It reports research that is part of a programme of work on first time mothers' expectations and experiences of postnatal care, including an online survey and cross sectional analyses of mothers' expectations and experiences, which will be reported separately.

\section{Methods}

\section{Study design}

This was a longitudinal qualitative descriptive study $(29,30)$, based on semi-structured, in-depth interviews, and underpinned by a contextualist approach $(31,32)$, which emphasises sequence and process within experiences. Qualitative longitudinal research focuses on process and change over time $(30,33,34)$. Data analysis may be repeat cross sectional - pooling cases to compare themes at different time points, or longitudinal - following individual trajectories over time $(30,35)$. This paper uses longitudinal trajectory analysis with a qualitative descriptive design (29) because the purpose of the study was to explore the relationship between participants' own expectations and experiences, and thus to stay close to their accounts without imposing a theoretical framework or generating theory (36). At the same time, this study acknowledges the roles of both participants' understandings and the researchers' interpretations in the production of knowledge $(32,37)$. Throughout the research process, the researchers worked with a reflexive awareness of their own perspectives on the transition to motherhood and postnatal care, based on professional knowledge and diverse personal experiences.

\section{Recruitment}

The criteria for participation in this study were that women were currently in the third trimester of pregnancy; aged 16 or over; planning to give birth in England and had not given birth previously. Purposive maximum variation sampling (38) was used to recruit women with a range of socio-demographic characteristics, with a particular emphasis on seeking diversity in age, socio-economic status and ethnicity. Four recruitment routes were used: [1] An online survey about expectations of postnatal care, promoted on social media by parent support organisations, at the end of which information was provided about the qualitative longitudinal research with an invitation for women to leave contact details if they wished to be considered. [2] Personal contact at a young mothers' antenatal group run by a community group in an area of high deprivation. A researcher attended three sessions of the group and invited young women attending to participate in the research. [3] Personal contact at a free antenatal exercise class run by a community group in another area of high deprivation. A researcher attended two sessions of the group and invited those attending to participate in the research. [4] An advertisement circulated on social media by a multiple birth charity. The researchers had no prior contact with any of the participants.

\section{Data collection}

Data were collected through two semi-structured qualitative interviews: the first when the participant was in the third trimester of pregnancy, and the second two to three months after birth. First interviews were carried out between October 2017 and March 2018, and second interviews in January-July 2018. Topic guides for the interviews are Additional Files 1 and 2 . Women for whom the research team had contact details were telephoned or emailed to confirm their willingness to participate in the research. If they agreed, they were emailed a participant information sheet and consent form at least 24 hours before the interview, which was carried out by telephone. Women with whom the researcher had face-to-face contact were given a participant information sheet and consent form and offered the options to take part in a face-to-face interview at a time and place of their choice, or a telephone interview.

Informed consent was obtained at the beginning of the interview through a signed consent form if face-to-face, or given orally and recorded in writing if by telephone. At the end of the first interview, participants were asked for permission for the researcher to contact them approximately six weeks after their baby's due date to arrange a second interview. Participants were offered a shopping voucher

Page 3/19 
worth $£ 10$ at the end of the first interview and a shopping voucher worth $£ 15$ at the end of the second interview, to thank them for their time. All interviews were carried out in English, although interpreting support was available if required. No one else was present at the face-to-face interviews. Interviews were audio-recorded and fully professionally transcribed.

In longitudinal qualitative research it is usual to over-recruit at the initial stage, to allow for the likelihood that some participants will be lost to follow up $(30,34)$. Data collection in this study therefore continued past the point where data saturation (39) was reached in first interviews, to allow for subsequent drop out and ensure demographic variation.

\section{Data analysis}

Longitudinal trajectory analysis (35) was carried out for the participants who completed both interviews, and focused on between-case analysis, where each case was the repeated interviews of a single participant over time (40). Longitudinal trajectory analysis is often used or presented for a small number of individual participants (41-43), because of the high volume of data generated through repeat interviews (40). This analysis sought to identify thematic patterns in the relationships between individual expectations, experiences and confidence of all participants.

Transcripts were checked against the audio-recordings, and read and reread for familiarity. Data from all the participants were charted into a matrix on an Excel spreadsheet, using the principles of framework analysis to condense data and incorporate verbatim quotations (41). The $Y$ axis was organised by participant. The $X$ axis was organised by topics derived from the research question: 'Hospital/birth centre expectations', 'Hospital/birth centre experiences', 'Community expectations', 'Community experiences', 'Postnatal support needs' and 'Impact on confidence'. To assist between-case analysis, additional columns were used on the X axis to classify (a) the participant's expectations of postnatal care as high, low or mixed, and specific or unformed, (b) her self-described postnatal support needs as high or low, (c) her experiences of care as high, low or mixed, (d) her self-described confidence at the time of second interview as high or low. Where there was a consistent pattern identified between expectations, experiences and outcomes for a number of participants, these were grouped together as a single trajectory. Particular attention was paid to negative cases that were anomalous to the emerging patterns. Two researchers (JM and FA) carried out the trajectory analysis independently, discussing and agreeing the emerging trajectories.

When the expectations, experiences and outcomes of all participants had been grouped into trajectories, the detail from the matrix was used to identify individuals who appeared to most clearly exemplify each trajectory. Where there was variation within a trajectory, more than one participant was identified to represent this variation. Participants were given pseudonyms and personally identifying detail was removed.

\section{Results}

\section{The participants}

Forty women took part in first interviews, at gestations between 27 and 40 weeks (median 38 weeks). Thirty two first interviews were by telephone and eight were face-to-face, ranging in length from 12-75 minutes (mean 31 minutes). Thirty two women (80\%) took part in second interviews, when their babies were 7-15 weeks old (median 11 weeks); eight women could not be contacted after birth. Twenty nine second interviews were by telephone and three were face-to-face, ranging in length from 21-56 minutes (mean 37.5 minutes).

The results reported in this paper are based on the 32 women who took part in both interviews. Background information about them is shown in Table 1. The eight mothers who were not contactable for second interviews were predominantly younger (six were under 25), more ethnically diverse (three identified as Black or Asian), and living in more disadvantaged areas (all were in the two most deprived quintiles, using the Index of Multiple Deprivation (45)).

\section{Expectations, experiences, and confidence: trajectories}

Across the 32 participants, expectations of postnatal care did not shape their appraisal of care as actually experienced. For many women these antenatal expectations were so unformed that there was little relationship with subsequent experiences of postnatal 
care. Others had developed more specific expectations; with some expecting high levels of postnatal support and some expecting low levels of support. Some women had high expectations because they knew in advance that they would have additional needs, for example as a young mother, as a mother of twins, or as a mother living with physical or mental illness. Others only identified a need for a higher level of support postnatally when they encountered unforeseen difficulties, for example with breastfeeding, with their baby's health, or with their own physical or mental health. Whatever the mother's expectations of care, the strongest influence on her satisfaction with postnatal care and her self-described parental confidence was not whether these expectations were met but rather the extent to which her actual postnatal needs for support were met.

Five trajectories, shown in Figure 1, were identified for all 32 women in the interplay between expectations, needs, experiences, and the mother's confidence at the time of second interview. There were three predominant trajectories [Trajectories 1-3] and two that were less common [Trajectories 4-5]. Because the level of a woman's expectations had such a limited impact on her experiences, these trajectories are organised around the differences in the level of support needed, support received and the impact on the woman's selfdescribed parental confidence. The differences between high or low expectations are explored within the descriptions of each trajectory.

Nine mothers have been chosen to illustrate the five identified trajectories, and their pseudonyms and characteristics are shown in Table 2. The first three trajectories are each represented by two or three mothers to illustrate the variation within these common trajectories based on differing levels of antenatal expectations. The last two, less common, trajectories are each represented by one mother.

\section{Trajectory 1. 'Low needs, low support, confident' (Amy and Beth)}

In this trajectory, women had high or low expectations of postnatal care, and low postnatal support needs. They had received basic support proportionate to their needs and had become confident mothers. Women who had low expectations of care, that were met or exceeded, were satisfied with the basic level of care received because it met both their needs and expectations. Women who had high expectations of care were disappointed in the care they received. However, because it met their needs they did not feel they had received inadequate care, nor that the disappointing care had negatively impacted their transition to motherhood.

Amy, who gave birth at home as planned, is an example of a mother who had limited expectations of postnatal care and felt that the basic support was better than she expected. In her antenatal interview she thought that there might be a single home visit from a midwife or health visitor on the day after birth, and expected them to focus on health checks for the baby. She was pleased to have three home visits from midwives, and then a visit from a health visitor which was much more positive than her expectations: "it was far more about helping us out, rather than checking up on us... I thought it [would be] a bit more social services type thing, like seeing if there was anything that we were doing wrong." After that visit she attended weighing clinics once a month where she was able to ask her questions, and found all the information to be consistent and reassuring: "It's been really useful to have somebody just go, 'No, it's fine,' because obviously you worry about every little detail". Amy said she felt confident right from the start: "the moment he was born it all just clicked into place", and she summarised her experience of postnatal care very positively in the light of how well routine care had met her straightforward needs: "Definitely got the right amount of support available, it's up to you whether you want to use it"..

Beth had high and specific expectations of "lovely" hospital postnatal care: "Help with feeding. Obviously I'll have the C-section, help with lifting the baby. And any mental health support really." Following a planned caesarean section, she at first received the high level of attentive support she had expected, in the recovery room and during the first 24 hours on the postnatal ward: "If I pressed the bell someone was there within a couple of minutes to help me, and they helped show me how to feed him, and changed his nappy." In other respects during her three day stay, her experience was less good than her high expectations. The ward environment was not restful with babies crying and upset mothers: "I didn't get any sleep... It wasn't ideal." Beth felt confused by conflicting information from staff about breastfeeding and swaddling: "it was all a bit contradictory, when you've not done it before. I didn't know who's right". She noticed that the midwives offered emotional support to mothers who were visibly distressed but (contrary to her expectations) not to her, although she was feeling stressed about being left alone at night when (also contrary to her expectations) her husband was not allowed to stay: "It was difficult without him ... I could have prepared myself mentally if I'd have known". Despite these issues, she felt that she was able to get the help she needed from staff: "No one treated you like you're being silly or using up too much of their time." 
In the community, Beth had expected home visits from a midwife and health visitor, but after one home visit from a midwife, the next two appointments were held at a clinic, which she found difficult to manage shortly after her caesarean section: "We weren't too pleased... Luckily my husband was still off, otherwise I don't know what l'd have done." She also described herself as "a bit disappointed" with the difficulty of accessing General Practitioner (GP) care: "It felt a bit like l'd just been left, once l'd been discharged from the midwife".. Nonetheless, Beth had recovered easily from the caesarean, had no difficulty breastfeeding, and described herself as confidently enjoying motherhood with her "laid back, easy" baby. While Beth's high expectations of postnatal care had not been met, she felt the care had been good enough: "We can't complain really ... I suppose I've not really had any issues, and if I had more issues it might have been more of a problem".

\section{Trajectory 2. 'High needs, high support, confident' (high expectations- Cristina, mixed expectations-Dana, low expectations-Evie)}

In this trajectory, women had high or low expectations of care, and had high postnatal support needs because of physical or mental health challenges, the baby's health problems, or difficulties breastfeeding. They had received high levels of support that both met their needs and met or exceeded their expectations. This led to high satisfaction with care and had enabled them to develop parental confidence despite the challenges they faced. Cristina had high initial expectations of care, Dana had mixed expectations and Evie had low expectations, but all of them described their postnatal care as exceeding their expectations.

When Cristina was pregnant with twins, she had pushed for information about care in hospital and particularly breastfeeding support; consequently she had well-defined high expectations. When her babies were born, she received a high level of support from staff who were "really great in trying to help establish breastfeeding". In particular she appreciated the intensive skilled assistance from maternity support workers, who gave her tips and reassurance and helped with feeding at night. Despite this support, breastfeeding did not go well, and Cristina's one criticism was that midwives had given contradictory assessments of the need to introduce supplementary feeding, and a few had been "brusque" and directive in their manner. Not knowing who to believe, she felt "pushed into starting formula".. Overall, however, she felt that her five days in hospital had been very useful: "I was by then feeling quite confident ... I think the support that I had whilst I was there was really key in moving me towards that".

Thinking ahead to care in the community, Cristina expected that as the mother of twins she might get extra visits from professionals. These expectations were fulfilled: "We were seen a little bit more regularly. Always at home, they would always come to us, I was never expected to have worked out how to get out and about with [the babies]". She was impressed that both her own postnatal medical complications and her babies' growth were carefully monitored, and appreciated that she had easy access to her health visitor: "It was comforting to know that we were being held in mind ... I can ring my health visitor at any time and ask her questions, or that she'll happily come out and see us again". Although it had been challenging for Cristina to come to terms with eventually giving up breastfeeding, her confidence had been boosted by affirmation from her health visitor: "the reassurance that my babies are doing okay and that I was managing okay and I was doing a good job". Overall Cristina felt that her postnatal care had both exceeded her high expectations and had met her high needs: "It's been better than I was expecting. When I was pregnant I don't think I really realised the care that I might need afterwards, all that follow-up care that's been given has been really excellent."

Dana, who had a mental health condition, had some clear expectations about care in hospital, some high and some low: "Right after the birth you'd probably be cared for very well, and you'll have some help with the baby and an opportunity to ask questions, but once you go down to the ward I think they might just let you try and get on with it yourself." Because of a medical complication Dana stayed on the labour ward for 12 hours after birth, and as she had expected, she received personalised support from an assigned midwife who checked her and her baby, and guided her in feeding and looking after her baby. Her expectation that there would be a lower level of care on the postnatal ward turned out to be well founded: "You definitely didn't have the focus of the midwives... you would see them three times a day, just for tablets and monitoring".. Nonetheless she had enjoyed this time in hospital: "It was still a very pleasant atmosphere for me and my partner, for our little family unit".

Dana had high expectations of care at home after hospital discharge, with "lots of medical visitors coming over the first few days" and more visits if she needed them. Although she found the midwives' visits rather chaotic, she received intensive support from the health visitor. This took the form of practical advice and emotional support when she was feeling low, and it exceeded her expectations: "She was very close during those weeks, seeing me every other week and also phoning and texting as well....She probably went above and beyond what l'd expect". She also felt that she had received exceptionally good support at home from "absolutely wonderful"

Page 6/19 
breastfeeding community support workers in the early weeks when she was struggling: "the hardest thing I have ever done... my boobs were broken". Her breastfeeding had become well established, but she believed that without this timely, intensive, home-based support she would have given up. She described how the person-centred care she had received after birth on the labour ward, and then from the breastfeeding support workers in the community to meet her high needs, had made all the difference:

"It was almost like I was the first person they'd ever dealt with who'd had a baby, and they gave me $100 \%$ of their care. It wasn't just their job that they'd done every day for the last however many years: I was really an individual with my own needs, and they fulfilled them".

By contrast to Cristina and Dana, Evie had very negative expectations of hospital postnatal care, having heard from friends that the midwives were "bossy". As a result of serious birth complications, Evie stayed in hospital for five nights, an experience which she "hated ... we wanted to just go home". Staff attitudes were, however, much better than she had expected: "They were really good ... I never really felt pushed aside or belittled or anything like that". She found staff were responsive: "When we asked for help we got help straightaway", although she did wonder whether this might be because she and her baby, who had additional health needs, were clinical priorities: "I had quite a lot of medical needs, and [my baby] was being quite closely monitored, so they had a lot more time for $m e$ ". Evie had mostly unformed and low expectations about postnatal care in the community: she was anticipating disempowering interactions with health professionals, because she had heard that midwives could be patronising, health visitors judgemental, and GPs cynical: "[GPs will say] 'Oh, it's just a worried mum again'... [The health visitor]'s just going to come in and lecture us about routine and weight gain". Her actual experience was quite different. She was pleasantly surprised to find that the "very friendly" midwives did home visits, and regretted not knowing this in advance, "because maybe that would have made me feel a bit less worried." Her health visitor turned out to be "very kind, not very intrusive... She gives all the things she has to give you but in a very non-lecturey way." The health visitor had made herself available to Evie by giving her a direct telephone number "so you can actually call them whenever you need them ... she'll even text and I'll text back." Evie really appreciated how the health visitor demonstrated a genuine concern for her and her baby, for example by personally inviting her to the weighing clinic, and following up on other appointments, "because it's like she's interested to know what's happening outside of what she's supposed to be doing". Evie had expected that professional reassurance would be important to her after birth, but she thought it was unlikely that she would get it. In fact, she found the support available exactly met her needs in this respect: "I think it's made me very confident because I've been able to ask all those silly questions when I needed to, so you're not constantly wondering, 'Am I doing this right?'”

Although most of Evie's experiences followed Trajectory 2, one aspect of her postnatal care did not fit this trajectory. Both she and her husband had significant unmet needs for professional support around a traumatic birth: "We both needed to talk about it ... we're both like, 'Oh my gosh, we'll only have one baby now because of that experience."' No health professional had discussed this with them. Although she had formed no antenatal expectations about this unforeseen scenario, Evie was worried about how her husband's wellbeing was completely overlooked in postnatal care: "They don't know that your husband's not sleeping at night and is really stressed and getting depressed ... [he] was there for every appointment with the midwife and the health visitor, but they never really spoke to him about anything."

\section{Trajectory 3. 'High needs, low support, not confident' (high expectations- Faith; low expectations-Gabi)}

In this trajectory, women had high or low expectations of care and high support needs. They had received inadequate support that did not meet their needs and were not confident. Women who had high expectations of care were disappointed in the care they received, because it had not met their needs or expectations. Women whose low expectations of care were met were nonetheless dissatisfied with the care received because it had not met their needs. Both Faith (who had high expectations) and Gabi (who had low expectations) had unresolved difficulties with breastfeeding; and they had lost confidence in themselves as mothers.

Faith's friends had suggested that that it was good to spend some time on the labour ward after birth because there was plenty of help offered. She was expecting the postnatal ward to be busy and noisy, but also expected that there would be good care, in particular support with breastfeeding, information and advice on baby care. She described her ideal hospital care as enabling both parents to "have a bit of a bubble around them while they're in this nice, shiny, new baby mode ... creating that bond as a family". 
Faith's stay in hospital was much worse than she expected, after a distressing birth that was "everything we hadn't prepared for and didn't want". Contrary to her high expectations about the labour ward, she felt abandoned for three hours after birth with no information: "We were like, 'What are we meant to do?' Because we didn't have a baby, now we've got a baby". She stayed for three nights on the postnatal ward and found it "very confused ... chaotic... a really loud, stressful, noisy, difficult environment" with babies crying all night and visiting children running around unsupervised during the day. Although she had expected noise, she had not imagined how exhausted and stressed she and her partner would feel. Far from being able to bond as a family in a protective bubble of care, they were both overwhelmed and she described her partner "absolutely shattered, and being sat in a chair next to me just sitting and going, 'What the f*** do we do now?'”

The main problem in hospital for Faith was that it was extremely difficult to get help when she needed it. Whereas she had expected that "there'll be lots of people around to support", the reality was that the midwives did not have time for her:

"They would say, 'Oh yes, I've just got to go do one thing and I'll be back immediately.' They're so busy that they go back into the corridors and get called away by 10 other people, so it would be about three or four hours sometimes, or more, before you'd see them again".

When she did receive breastfeeding support it was not what she needed: "There was a lot of advice, but not really helpful advice". For example, a lactation consultant positioned the baby for feeding without explaining: "She thought she was showing me what to do, she was actually just doing it... After about five minutes it was like, 'I've no idea what she just did.'". She was expecting other advice on looking after her baby, but found the way that it was delivered in hospital to be contradictory, disempowering and undermining of her own instincts about what was right for her baby.

Faith had no clear expectations about community postnatal care; she had heard there would be a health visitor but did not know what a health visitor was, although she understood that they "could be quite critical of your home or your way of parenting".. She found that community midwives were unreliable and hard to contact. She also discovered that she could not take their advice at face value, after they directly contradicted each other. Despite what Faith had heard about health visitors, she found hers "lovely", although there was an element of scrutiny: "She wanted to see our bedroom, and I think just to check on how safe our home was". Faith was left with many unanswered questions about baby care: "It's not really been how to be a parent", but had no one else to ask: "We don't have family support here because all our families are in [home country]."'

At home, her difficulties with breastfeeding continued. She was referred to a support group but found it too hard to leave the house with a newborn. She found a community volunteer's reassurance that she was feeding correctly to be unhelpful when her baby was not thriving. Anxiety about her baby's failure to gain weight, coupled with pressure from professionals to introduce formula, was intensely stressful for Faith. She had believed antenatally that she had realistic expectations about becoming a mother: "I certainly don't expect to be a perfect mum straightaway, and probably not ever... then I won't be disappointed". However, her experience of confusing, unreliable and insufficient postnatal care had left her "struggling", and she reflected that "different or better feeding support would have just really changed our lives".

Gabi had only vague expectations of hospital care, but had gathered that her medical condition would be monitored and that she could transfer to a freestanding birth centre if she needed help with breastfeeding. Both of these expectations were fulfilled, but before moving to the birth centre she had two unpleasant and sleepless nights on a postnatal ward, which was hot and noisy from other babies, mothers and visitors: "I would not like to repeat that experience". Her husband was sent home when she was transferred to the postnatal ward, and she was left on her own overnight, feeling abandoned and disorientated: "I just had this tiny life clinging to my chest and I didn't know what to do." The overstretched midwives came if called, but did not have time to see if their advice about breastfeeding was effective:

"They would have to go off and help somebody else without being able to spend time actually making sure you were doing it and it was working. So, I would try something, it didn't work, I would then have to call them again a little bit later, they'd come back and say try something else".

When her buzzer stopped working she was no longer able to ask for help and felt completely isolated: "it was all a bit of a nightmare." After two nights she was still struggling with breastfeeding and transferred to the freestanding birth centre where she had "a wildly different experience" of personalised support due to the low midwife-to-woman ratio. 
Gabi also had low expectations about postnatal care in the community. She was unclear about whether midwives would be involved, or the role of the health visitor, or whether there would be home visits. Although she felt quite confident when she was discharged from the birth centre, ongoing difficulties with feeding undermined this: "As the weeks went on [I] lost confidence because of my baby's weight gain not being sufficient". Her baby had to be weighed every few days and for some of these she had to take her baby to the hospital, where she found the protracted waits of up to 90 minutes very stressful. It was also difficult to contact the health visitor when Gabi needed her help:

"There were a few times when we were really at our worst and struggling where I phoned up and couldn't get through ... or left a message for them and it would be at least 24 hours before they were able to return a call".

The health visitors' clinics were inhospitable to new mothers because they were held first thing in the morning, "which is practically the middle of the night sometimes to try and get out the house", in a noisy playgroup which did not allow pushchairs: "There's nowhere to sit down when you're in there, so if baby is sleeping you have to walk around with your baby in your arms until they can see you."

Gabi felt that she had largely been left to try to solve her own feeding problems with the help of "Doctor Google". Like Faith, contradictory advice from professionals had led her to doubt her own judgement:

"One piece of advice I was given was, 'Don't do what people tell you to do, trust your instincts,' but I felt like my instincts were nonexistent by the time I was given that advice because we'd been given so many different conflicting bits of information."

She said that the repeated frequent weighing of her baby had made her feel judged: "I still feel under immense pressure... I feel like all the time I'm being scrutinised as my ability as a mother". Gabi had received no wider reassurance to affirm her competence in the face of these difficulties, and her parenting confidence had collapsed: "I basically doubt every single thing I do with him".

\section{Trajectory 4. 'High needs, high support, additional risk factors, not confident' (high expectations - Holly)}

In this trajectory, women had high expectations of care, had high support needs, received high levels of support, and were satisfied with their care which met their expectations. However, due to social or mental health complexity this high level of support had not enabled them to become confident mothers.

Holly, who was a young, single mother, had not formed any expectations at all about postnatal care in hospital: she was focused on birth and when she thought about the time after birth it was in practical, personal terms: "I don't have to walk around with extra weight... you get to bring your own clothing I guess". Holly had to stay a week in hospital due to a medical complication, and found this time "very boring". Her mother stayed with her, looking after her and the baby and helping her to breastfeed. She found the staff friendly and saw their role as "just making sure I'm well and the baby is well".

Holly's postnatal care experiences were dominated by the fact that when discharged from hospital she was required to live at a mother and baby foster placement; if she did not pass a parenting assessment, her baby would be removed from her care. She described the experience of being a new mother while living away from her own mother and being constantly assessed as "sad ... strange...

stressful". She was expecting home visits from her teenage pregnancy midwife and a health visitor, although she was not sure how long the midwifery care would continue: "[The midwife] said she'll be with me forever, so... but I think that was a joke". She explained the difference between what she expected from these two professionals: "[The midwife] is more about me but it is about the baby as well, but with the health visitor it's more about the baby than me, but it is about me".

These expectations were borne out in practice. She did not rate information from the midwife or health visitor as particularly useful, because "most of my family members, they have babies already, so I already know quite a lot". She was, however, careful to seek out and follow the advice of health professionals, to increase her chances of passing the assessment: "I confirm, as in I always go to my mum and then I'll just double check [with the professionals], so say for example [the baby] reacts badly to whatever I've done, I can be like, 'Well, we all confirmed it'". Like other young mothers in this study, she found it difficult to balance appropriate advice-seeking with demonstrating parenting competence, when the rules appeared subjective. The foster carer's role was experienced as an uncomfortable blend of assistance and judgement: "It's got to be done their way, not your way...[they] set you up to fail, because they 
expect you to know how to do it already". Despite high level of support she received, Holly found the realities of motherhood overwhelming:

"You know when after you've given birth you just want the baby? When he was sleeping, I just wanted to wake him up. But then, a month after, you just want him to sleep ... when the baby is too much I can give him to [the foster mother]."

\section{Trajectory 5. 'High needs, low support, additional protective factors, confident' (low expectations - Jacqui)}

In this trajectory, women had low expectations of care, and had high support needs. They did not receive the support they needed, and were dissatisfied with their care. Unlike the women in Trajectory 3, they had nonetheless become confident parents through the support of family or their own existing self-efficacy, which buffered the impact of inadequate professional support.

Jacqui did not expect much from her hospital care: "I think they would probably check if I'm okay with feeding and then just send me off". Likewise she had limited expectations of care in the community, which she knew would involve midwives and a health visitor but not when, where or why; she said that if she encountered a problem she expected to ask for their help or "look it up, or just sort of handle it". The care she received during a brief postnatal stay of less than 24 hours in hospital did not even meet these low expectations:

"I only had people coming in doing the exit stuff with me, filling in checks and stuff like that... I did ask a couple of midwives to help me settle [my baby] ... and they just suggested a couple of things and then went away and didn't really help."

When discharged, Jacqui was far from "okay with feeding": "I had quite a lot of nerve pain in my breast and my back, I had blood coming from my nipples and they were shredded to pieces". She appreciated that a midwife and the health visitor came out to check on her, but described their care as "quite minimal"; they did not give her useful support, and she found the health visitor "was just there for some things that they have to do...quite bland". She was referred to a breastfeeding group at a time when she could barely leave the house, and to a lactation consultant, whose advice she did not find helpful. Jacqui had been "on the verge of giving up" but, unlike Faith and Gaby, inadequate professional support did not destroy her confidence in her own judgement. She did her own research and found her own solutions, "based on Google searching and seeing what other people have done in a similar position". She noted that this went against the advice she was given: "the NHS hospitals aren't very keen on how I solve my own problems... but I think the best support I got was just finding out for myself". She had gone on to establish breastfeeding successfully, but she felt that this was despite, not because of, her postnatal care which had "made it a bit more of a rocky start".

\section{Discussion}

This study illustrates how first time mothers in England had varied expectations of postnatal care during the third trimester of pregnancy, ranging from low to high and from unformed to specific. They also had a wide range of subsequent experiences of care, ranging from positive to negative, some of which met or exceeded their expectations and some of which disappointed them. Repeat cross-sectional studies of expectations and experiences cannot go beyond these generalisations $(8,46)$, but trajectory analysis has enabled the links between expectations, experiences, appraisal of care and parental confidence to be tracked for each individual and then analysed for common patterns. These patterns, reported as five trajectories, are inevitably to some extent simplifications, because some mothers experienced what they considered to be good postnatal care in some respects and poor care in others. The trajectories are nonetheless meaningful in representing repeated patterns in individual women's expectations, their appraisal of care they received, and their perceptions of its consequences for themselves.

This analysis has demonstrated that, as argued by Pascoe (21) and Thompson and Sunol (22), and as reported by Hirst and Hewison (8), predicted expectations did not shape satisfaction with postnatal care for any of the mothers. Instead this was primarily influenced by the extent to which the care received met the mother's actual postnatal needs, which were not necessarily foreseeable in pregnancy. Mothers could be both disappointed that postnatal care did not meet high expectations and yet satisfied with it as meeting need. Conversely having low expectations of care did not make it easier to cope when these expectations were realised, for example expectation that the postnatal ward would be noisy and busy did not help a mother to deal with the resulting exhaustion and lack of staff attention. This is in line with Pascoe's conceptualisation of healthcare satisfaction as a cognitive evaluation of, and affective 
response to, the "context, process and result of their service experience" (21). Pascoe argues that cognitive evaluation involves comparison against an individually identified standard, in this case the mother's subjective perception of the extent to which care received was proportionate to her needs. It was not the structure of the postnatal care that was important to mothers $(23,47)$, so much as the timely availability of access to support when needed, and the quality of the interactions with the health professionals providing care.

This is not to argue that it is unimportant for women to have accurate information during pregnancy about postnatal care. Mothers who had limited advance information about postnatal care worried unnecessarily that they would be unsupported, or were unable to plan ahead. Some mothers from varied socio-demographic backgrounds expressed very negative expectations about judgmental health visitors, which sometimes contrasted with subsequent positive experiences. Canvin et al. (48) and Kurtz et al. (49) have highlighted how negative expectations may have significant consequences for some disadvantaged mothers, whose fears about being judged or reported to social services lead them to not engage with the health visiting service.

This study provides evidence in support of the contention that high quality, needs-led professional support in the postnatal period plays a key role in enabling first time mothers to make a confident transition to parenthood $(2,50)$, by providing positive feedback and direct support to master skills such as infant care and feeding $(12,13,15,23)$. Trajectory 2 shows how high support matched to high need can enable mothers to overcome the challenges they face, while Trajectory 3 shows that a lack of support, or high quantity of support contacts experienced by mothers as low quality, can undermine their ability to develop their parental confidence.Unresolved challenges with breastfeeding were prominent as an obstacle to developing confidence and maternal emotional wellbeing in this trajectory, consistent with evidence that successful breastfeeding is associated with better maternal mental health for women who plan to breastfeed (51).

These findings also illustrate the importance of high quality postnatal care across the care continuum between hospital or birth centre and the community, in the context of the reduced length of average time spent by new mothers on a postnatal ward (52-54). The contrasting community experiences of mothers in Trajectories 2 and 3 suggest that in some areas, the current ' $4-5-6$ ' model of health visiting (55) was being successfully delivered, in particular the 'Universal Plus' offer of increased support to mothers with higher needs, but in other areas this was failing. The variation in community-based postnatal care available in different parts of England and Wales has been criticised as an unacceptable "postcode lottery" (56), with inconsistent adherence to the postnatal care recommendations of the National Institute for Health and Clinical Excellence (2). Although there has been targeted government funding to develop perinatal mental health services (57), this has not been matched by investment in ordinary postnatal care, which has the potential to prevent some mental health problems from developing $(11,51)$.

Trajectories 4 and 5 illustrate exceptions to the general pattern. Trajectory 5 demonstrates how for some women, the impact of insufficient postnatal care could be buffered by social support in the community $(15,58)$, or mitigated by strong pre-existing personal self-efficacy $(11,12,59)$. This is consistent with Young and Roberts' findings in their review of the application of resilience theories in the transition to parenthood (60). Trajectory 4 shows the opposite situation: there were some women whose needs were so complex that they were not met even by a level of postnatal care which the mothers themselves considered good. This suggests the importance of postnatal care being embedded in a joined-up, multi-agency response to vulnerable mothers' needs, and indicates the benefits of the sustained, intensive support given to young mothers in programmes such as the Family Nurse Partnership, which may improve maternal self-efficacy (61).

Trajectory 4 also shows the limitations of postnatal care in supporting the development of a mother's skills and confidence where there are safeguarding concerns about her ability to care for the baby. Knight and colleagues highlighted the lack of guidance or specialist training for mother and baby foster carers, with foster carers unclear about the expected parameters of their role (62). Mantovani and Thomas' study of Black teenage mothers in foster care demonstrated the variability in foster carers' willingness and ability to provide effective emotional support for young mothers during the transition to parenthood (63). Given the challenges that most first time mothers face in developing their own parenting confidence when they are not separated from their partners and support networks, it may be questioned whether the most effective way to enable vulnerable women to become competent and confident parents is through placement with a carer without specialist training. Further research could investigate ways in which postnatal care can be most effectively adapted to meet the individual needs of mothers and babies who are vulnerable or have additional needs, and how postnatal care professionals can work with partners outside the health service to improve the care offered to new mothers in the community. 


\section{Strengths and limitations}

It was a strength of this research that it included 32 women from across England and from a variety of socio-demographic backgrounds. The qualitative longitudinal design using trajectory analysis enabled the rich, in-depth exploration of the relationship between women's expectations about postnatal care and subsequent experiences, appraisal of care and outcomes.

It was a limitation that the mothers who were lost to follow-up were younger, more socio-economically disadvantaged, and more ethnically diverse than those who took part in second interviews.

\section{Conclusion}

Longitudinal qualitative research using trajectory analysis is a useful and feasible method of exploring predicted expectations and subsequent experiences in the perinatal period. First time mothers' satisfaction with postnatal care and their confidence as new mothers were primarily influenced not by the extent to which their expectations were met, but the varied extent to which their postnatal needs were met. Rapid and responsive assessment of needs both antenatally and postnatally, and appropriate adjustment of care, is key in supporting women effectively at this time. Providing tailored information on postnatal care, self-care and transition to parenthood during pregnancy may facilitate improvements in women's experiences of care after birth in the hospital and community.

\section{Declarations}

\section{Abbreviations}

Not applicable

\section{Ethics approval}

The University of Oxford Medical Sciences Inter-Divisional Research Ethics Committee (reference R52703/RE001) approved the study.

\section{Consent to participate and for publication}

An information leaflet was provided and informed consent to participate was obtained, through a signed consent form if interviewed face-to-face, or given orally and recorded in writing if interviewed by telephone. Women consented to data collection and for their interview responses to be used in publications with no details or other information being published that could identify them.

\section{Availability of data and materials}

Following the consent process the individual qualitative interview transcripts will not be made publicly available.

\section{Competing interests}

Maggie Redshaw is an Associate Editor of BMC Pregnancy and Childbirth.

The other authors declare they have no competing interests.

\section{Funding}

This paper reports on an independent study which is funded by the Policy Research Programme in the Department of Health. The views expressed are not necessarily those of the Department of Health.

\section{Author Contributions}


This study is part of a programme of work, the research questions for which were developed by MR and FA. JM, FA, MR, MH, RM and $\mathrm{JH}$ were involved in the design of the study. JM and MH undertook the data collection and JM and FA took part in data analysis. JM drafted the manuscript with input from FA and MR. All authors were involved in interpretation, review and revision of the draft manuscript and approval of the final version.

\section{Acknowledgements}

We are most grateful to all the women who participated in this study and the organisations and individuals who facilitated the research: NCT, Babycentre, TAMBA, Island House Community Parents, Lucy November.

\section{References}

1.National Maternity Review. Better Births: Improving outcomes of maternity services in England. NHS England; 2016.

2.National Institute for Health and Clinical Excellence. Routine postnatal care of women and their babies. NICE clinical guideline 37 London: NICE; 2006.

3.Redshaw M, Henderson J. Safely delivered: a national survey of women's experience of maternity care 2014. Oxford: National Perinatal Epidemiology Unit, University of Oxford; 2015.

4.Davies SC. Annual Report of the Chief Medical Officer, 2014, The Health of the 51\%: Women. London: Department of Health 2015.

5.Royal College of Midwives. Postnatal care planning. London: RCM; 2014.

6.Beake S, McCourt C, Bick D. Women's views of hospital and community-based postnatal care: the good, the bad and the indifferent. Evidence Based Midwifery. 2005;3(2):80-6.

7.Dykes F. A critical ethnographic study of encounters between midwives and breast-feeding women in postnatal wards in England. Midwifery. 2005;21(3):241-52.

8. Hirst J, Hewison J. Hospital postnatal care: obtaining the views of Pakistani and indigenous 'white' women. Clin Eff Nurs. 2002;6(1):10-8.

9.Fawcett J. The impact of postnatal care on a woman's overall maternity experience: an analysis of stories from Patient Opinion. Sheffield: Sheffield Medical School; 2016.

10.Lagan BM, Symon A, Dalzell J, Whitford H. 'The midwives aren't allowed to tell you': perceived infant feeding policy restrictions in a formula feeding culture - the Feeding Your Baby Study. Midwifery. 2014;30(3):e49-55.

11.Leahy-Warren P, McCarthy G. Maternal parental self-efficacy in the postpartum period. Midwifery. 2011;27(6):802-10.

12.Bandura A. Self-efficacy: Toward a Unifying Theory of Behaviour Change. Psychol Rev. 1977;84:191-215.

13.Barclay L, Everitt L, Rogan F, Schmied V, Wyllie A. Becoming a mother-an analysis of women's experience of early motherhood. J Adv Nurs. 1997;25(4):719-28.

14.Wiegers TA. Adjusting to motherhood: Maternity care assistance during the postpartum period: How to help new mothers cope. J Neonatal Nurs. 2006;12(5):163-71.

15.Leahy Warren P. First-time mothers: social support and confidence in infant care. J Adv Nurs. 2005;50(5):479-88.

16.Puthussery S, Twamley K, Macfarlane A, Harding S, Baron M. 'You need that loving tender care': maternity care experiences and expectations of ethnic minority women born in the United Kingdom. J Health Serv Res Policy. 2010;15(3):156-62.

17.Beake S, Rose V, Bick D, Weavers A, Wray J. A qualitative study of the experiences and expectations of women receiving in-patient postnatal care in one English maternity unit. BMC Pregnancy Childbirth. 2010;10:70.

Page 13/19 
18.Jomeen J, Redshaw M. Ethnic minority women's experience of maternity services in England. Ethn Health. 2013;18(3):280-96.

19.Linder-Pelz S. Social psychological determinants of patient satisfaction: a test of five hypothesis. Soc Sci Med. 1982;16(5):583-9.

20.Jackson JL, Chamberlin J, Kroenke K. Predictors of patient satisfaction. Soc Sci Med. 2001;52(4):609-20.

21.Pascoe GC. Patient satisfaction in primary health care: A literature review and analysis. Eval Program Plann. 1983;6(3):185-210.

22.Thompson AG, Sunol R. Expectations as determinants of patient satisfaction: concepts, theory and evidence. Int J Qual Health Care. 1995;7(2):127-41.

23.Forster DA, McLachlan HL, Rayner J, Yelland J, Gold L, Rayner S. The early postnatal period: Exploring women's views, expectations and experiences of care using focus groups in Victoria, Australia. BMC Pregnancy Childbirth. 2008;8(1):27.

24.Lindberg I, Öhrling K, Christensson K. Expectations of post-partum care among pregnant women living in the north of Sweden. Int J Circumpolar Health. 2008;67(5):472-83.

25.Bowling A, Rowe G, Lambert N, Waddington M, Mahtani KR, Kenten C, et al. The measurement of patients' expectations for health care: a review and psychometric testing of a measure of patients' expectations. Health Technol Assess. 2012;16(30):i-xii, 1-509.

26.Scott J, Alwin D. Retrospective versus Prospective Measurement of Life Histories in Longitudinal Research In: Giele JZ, Elder Jr GH, editors. Methods of Life Course Research: Qualitative and Quantitative Approaches. Thousand Oaks, CA: Sage Publications; 1998.

27.Redshaw M, Henderson J. Learning the Hard Way: Expectations and Experiences of Infant Feeding Support. Birth. 2012;39(1):21-9.

28.Ockleford EM, Berryman JC, Hsu R. Postnatal care: what new mothers say. Br J Midwifery. 2004;12(3):166-70.

29.Sandelowski M. Whatever Happened to Qualitative Description? Res Nurs Health. 2000;23:334-40.

30.Thomson R, Holland J. Hindsight, foresight and insight: The challenges of longitudinal qualitative research. Int J Soc Res Methodol. 2003;6(3):233-44.

31.Mjøset L. The contextualist approach to social science methodology. In: Byrne D, Ragin CC, editors. The SAGE Handbook of CaseBased Methods. London: SAGE; 2009. p. 39-68.

32.Madill A, Jordan A, Shirley C. Objectivity and reliability in qualitative analysis: Realist, contextualist and radical constructionist epistemologies. Br J Psychol. 2000;91(1):1-20.

33.Saldaña J. Analyzing Change in Longitudinal Qualitative Data. Youth Theatre Journal. 2002;16(1):1-17.

34.Hermanowicz JC. The longitudinal qualitative interview. Qual Sociol. 2013;36(2):189-208.

35.Grossoehme D, Lipstein E. Analyzing longitudinal qualitative data: the application of trajectory and recurrent cross-sectional approaches. BMC Res Notes. 2016;9:136.

36.Tindall C. Issues of evaluation. In: Banister P, Burman E, Parker I, Taylor M, Tindall C, editors. Qualitative methods in psychology: A research guide. Buckingham: Open University Press; 1994.

37.Sandelowski M. What's in a name? Qualitative description revisited. Res Nurs Health. 2010;33(1):77-84.

38.Patton MQ. Qualitative Research \& Evaluation Methods. 3rd ed. Thousand Oaks, CA: Sage Publications; 2002.

39.Saunders B, Sim J, Kingstone T, Baker S, Waterfield J, Bartlam B, et al. Saturation in qualitative research: exploring its conceptualization and operationalization. Qual Quant. 2018;52(4):1893-907.

40.Calman L, Brunton L, Molassiotis A. Developing longitudinal qualitative designs: lessons learned and recommendations for health services research. BMC Med Res Methodol. 2013;13(1):14.

41.Snelgrove SR. Conducting qualitative longitudinal research using interpretative phenomenological analysis. Nurse Res. 2014;22(1).

Page 14/19 
42.Kelly C, Alderdice F, Lohan M, Spence D. Creating continuity out of the disruption of a diagnosis of HIV during pregnancy. J Clin Nurs. 2012;21(11-12):1554-62.

43.Thomson R. The Qualitative Longitudinal Case History: Practical, Methodological and Ethical Reflections. Soc Policy Soc. 2007;6(4):571-82.

44.Ritchie J, Lewis J. Qualitative research practice: a guide for social science students and researchers. London: Sage Publications; 2003.

45.Ministry of Housing Communities and Local Government. English indices of deprivation 2015 http://imd-bypostcode.opendatacommunities.org/ Accessed 21 November 2018.

46.Deave T, Johnson D, Ingram J. Transition to parenthood: the needs of parents in pregnancy and early parenthood. BMC Pregnancy Childbirth. 2008;8:30.

47.Miller YD, Dane AC, Thompson R. A call for better care: the impact of postnatal contact services on women's parenting confidence and experiences of postpartum care in Queensland, Australia. BMC Health Serv Res. 2014;14:635.

48.Canvin K, Jones C, Marttila A, Burström B, Whitehead M. Can I risk using public services? Perceived consequences of seeking help and health care among households living in poverty: qualitative study. J Epidemiol Community Health. 2007;61(11):984-9.

49.Kurtz Z, McLeish J, Arora A, Ball M. Maternity Services Provision in Sure Start Local Programmes. London: Department for Education and Skills 2005.

50.Public Health England. Early years high impact area 1: Transition to parenthood. Health visitors leading the Healthy Child Programme. London: Public Health England; 2018.

51.Borra C, lacovou M, Sevilla A. New Evidence on Breastfeeding and Postpartum Depression: The Importance of Understanding Women's Intentions. Matern Child Health J. 2015;19(4):897-907.

52.Bowers J, Cheyne H. Reducing the length of postnatal hospital stay: implications for cost and quality of care. BMC Health Serv Res. 2016;16:16.

53.Nilsson I, Danbjorg DB, Aagaard H, Strandberg-Larsen K, Clemensen J, Kronborg H. Parental experiences of early postnatal discharge: A meta-synthesis. Midwifery. 2015;31(10):926-34.

54.Fink AM. Early hospital discharge in maternal and newborn care. J Obstet Gynecol Neonatal Nurs. 2011;40(2):149-56.

55.Public Health England. Best start in life and beyond: Improving public health outcomes for children, young people and families. Guidance to support the commissioning of the Healthy Child Programme 0-19: Health visiting and school nursing services. London: Public Health England; 2018.

56. The National Federation of Women's Institutes and NCT. Support Overdue: Women's experiences of maternity services 2013.

57.NHS England. Perinatal 2018 https://www.england.nhs.uk/mental-health/perinatal/ Accessed 7 July 2018.

58.Cohen S, Wills TA. Stress, social support, and the buffering hypothesis. Psychol Bull. 1985;98(2):310-57.

59.Vance AJ, Brandon DH. Delineating Among Parenting Confidence, Parenting Self-Efficacy, and Competence. ANS Adv Nurs Sci. 2017;40(4):E18-E37.

60.Young C, Roberts R, Ward L. Application of resilience theories in the transition to parenthood: a scoping review. J Reprod Infant Psychol. 2018:1-22.

61.Robling M, Bekkers M-J, Bell K, Butler CC, Cannings-John R, Channon S, et al. Effectiveness of a nurse-led intensive home-visitation programme for first-time teenage mothers (Building Blocks): a pragmatic randomised controlled trial. Lancet. 2016;387(10014):14655. 
62.Knight A, Chase E, Aggleton P. Teenage Pregnancy among Young People in and Leaving Care: Messages and Implications for Foster Care. Adopt Foster. 2006;30(1):58-69.

63.Mantovani N, Thomas H. Resilience and Survival: Black Teenage Mothers 'Looked After' by the State Tell their Stories About their Experience of Care. Child Soc. 2015;29(4):299-309.

\section{Tables}

Table 1: Background information about participants 


\begin{tabular}{|c|c|}
\hline & Number of participants (\%) \\
\hline \multicolumn{2}{|l|}{ Age } \\
\hline Under 25 years & $3(9.38 \%)$ \\
\hline 25-29 years & $10(31.25 \%)$ \\
\hline 30-34 years & $10(31.25 \%)$ \\
\hline $35+$ years & $9(28.12 \%)$ \\
\hline \multicolumn{2}{|l|}{ Ethnicity } \\
\hline White & $26(81.25 \%)$ \\
\hline Mixed or multiple ethnicity & $4(12.5 \%)$ \\
\hline Black & $1(3.12 \%)$ \\
\hline Asian & $1(3.12 \%)$ \\
\hline \multicolumn{2}{|l|}{ Country of origin } \\
\hline UK & $27(84.38 \%)$ \\
\hline Outside UK & $5(15.62 \%)$ \\
\hline \multicolumn{2}{|c|}{ Index of Multiple Deprivation quintile postcode classification(45) } \\
\hline Quintile 1 (most deprived) & $5(15.62 \%)$ \\
\hline Quintile 2 & $4(12.5 \%)$ \\
\hline Quintile 3 & $10(31.25 \%)$ \\
\hline Quintile 4 & 7 (21.87\%) \\
\hline Quintile 5 (least deprived) & $7(21.87 \%)$ \\
\hline \multicolumn{2}{|c|}{ Planned place of birth } \\
\hline Birth centre & $20(62.5 \%)$ \\
\hline Labour ward & $11(34.37 \%)$ \\
\hline Home & $1(3.12 \%)$ \\
\hline \multicolumn{2}{|c|}{ Actual place of birth } \\
\hline Birth centre & $4(12.5 \%)$ \\
\hline Labour ward & $27(64.37 \%)$ \\
\hline Home & $1(3.12 \%)$ \\
\hline \multicolumn{2}{|l|}{ Type of birth } \\
\hline Spontaneous vaginal birth & $13(40.62 \%)$ \\
\hline Unassisted vaginal birth following induction & $2(6.25 \%)$ \\
\hline Assisted birth & $9(28.12 \%)$ \\
\hline Caesarean section & $8(25 \%)$ \\
\hline \multicolumn{2}{|c|}{ Length of stay on postnatal ward or at birth centre $(n=31)$} \\
\hline$<1$ night & $1(3.23 \%)$ \\
\hline 1 night & $11(35.48 \%)$ \\
\hline 2 nights & $11(35.48 \%)$ \\
\hline 3 nights & $2(6.46 \%)$ \\
\hline 4 nights & $1(3.23 \%)$ \\
\hline 5 nights & $2(6.46 \%)$ \\
\hline 6 nights & $3(9.68 \%)$ \\
\hline
\end{tabular}




\begin{tabular}{|c|c|c|c|c|c|c|c|c|c|c|}
\hline $\begin{array}{l}\text { Trajectory } \\
\text { number }\end{array}$ & $\begin{array}{l}\text { Pseudo- } \\
\text { nym }\end{array}$ & $\begin{array}{l}\text { Age in } \\
\text { years }\end{array}$ & Ethnicity & $\begin{array}{l}\text { IMD } \\
\text { quintile* }\end{array}$ & Type of birth & Expectations & $\begin{array}{l}\text { Postnatal } \\
\text { needs }\end{array}$ & $\begin{array}{l}\text { Postnatal } \\
\text { support } \\
\text { received }\end{array}$ & $\begin{array}{l}\text { Expectations } \\
\text { met }\end{array}$ & $\begin{array}{l}\text { Parental } \\
\text { Confidence }\end{array}$ \\
\hline 1 & Amy & $25-29$ & White & 1 & Home/ vaginal & Low/unformed & Low & Low & Exceeded & High \\
\hline 1 & Beth & $25-29$ & White & 4 & $\begin{array}{l}\text { Hospital/ planned } \\
\text { caesarean }\end{array}$ & High/specific & Low & Low & Not met & High \\
\hline 2 & Cristina & $30-34$ & Mixed & 3 & $\begin{array}{l}\text { Hospital/ vaginal } \\
\text { (twins) }\end{array}$ & High/specific & High & High & Exceeded & High \\
\hline 2 & Dana & $30-34$ & White & 4 & $\begin{array}{l}\text { Hospital/ } \\
\text { emergency } \\
\text { caesarean }\end{array}$ & Mixed/specific & High & High & Exceeded & High \\
\hline 2 & Evie & \begin{tabular}{|l|} 
Under \\
25 \\
\end{tabular} & White & 2 & Hospital/ vaginal & Low/unformed & High & High/low & Exceeded & High \\
\hline 3 & Faith & $30-34$ & White & 5 & Hospital/ventouse & High/unformed & High & Low & Not met & Low \\
\hline 3 & Gabi & $30-34$ & White & 3 & $\begin{array}{l}\text { Hospital/ vaginal } \\
\text { after induction }\end{array}$ & Low/unformed & High & Low & Not met & Low \\
\hline 4 & Holly & \begin{tabular}{|l|} 
Under \\
25 \\
\end{tabular} & Black & 1 & Hospital/vaginal & High/unformed & High & High & Met & Low \\
\hline 5 & Jacqui & $30-34$ & White & 4 & Hospital/vaginal & Low/unformed & High & Low & Not met & High \\
\hline
\end{tabular}

*Quintile 1 is the most socio-economically deprived, quintile 5 the least deprived

Figures 


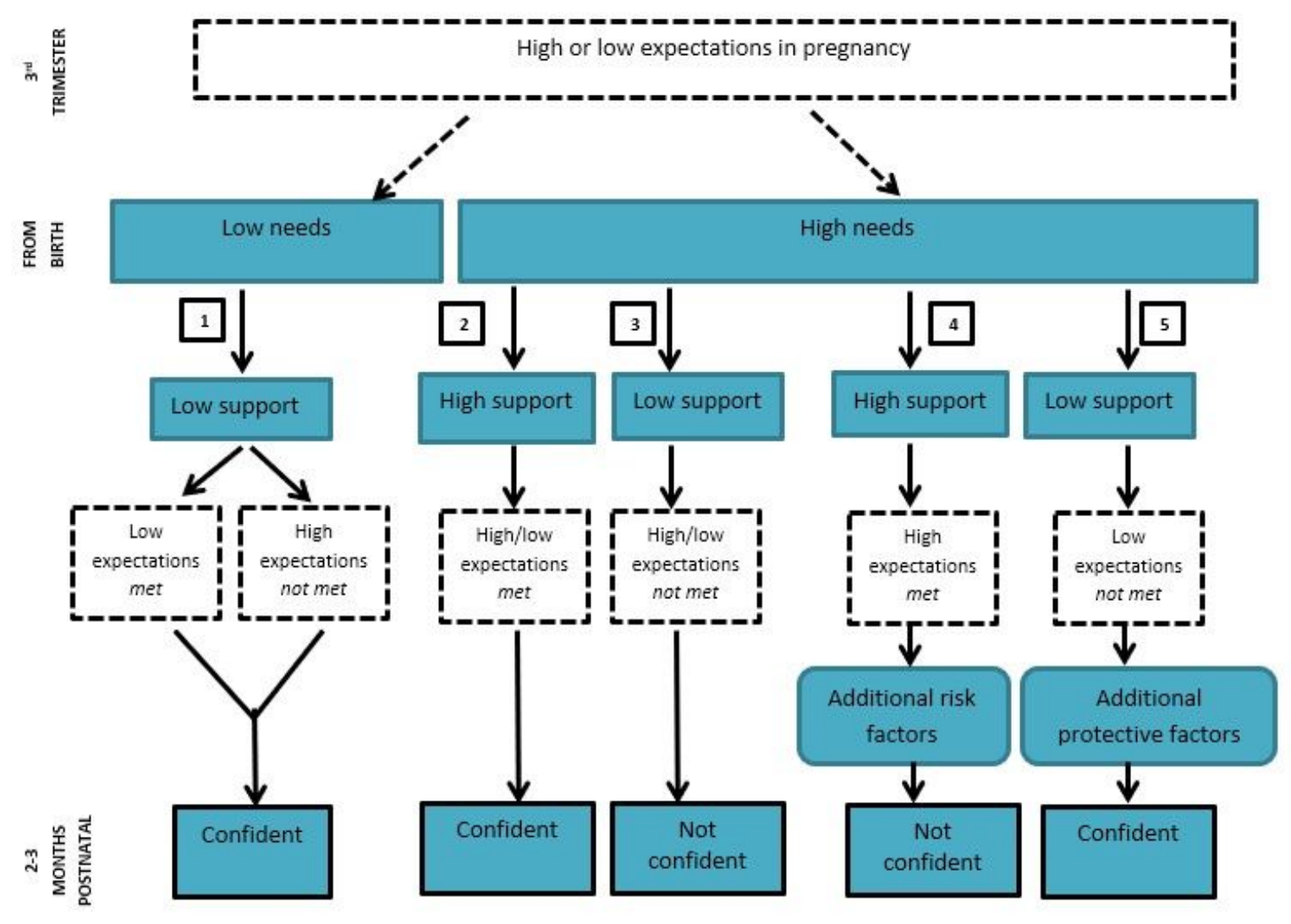

\section{Key - 5 Trajectories}

\begin{tabular}{|l|l}
\hline 1 & 'Low needs, low support, confident' \\
\hline 2 & 'High needs, high support, confident' \\
\hline 3 & 'High needs, low support, not confident' \\
\hline 4 & 'High needs, high support, additional risk factors, not confident' \\
\hline 5 & 'High needs, low support, additional protective factors, confident'
\end{tabular}

\section{Figure 1}

Trajectories between expectations, postnatal needs, postnatal care received and self-described parental confidence at 3 months

\section{Supplementary Files}

This is a list of supplementary files associated with this preprint. Click to download.

- Additionalfile2.docx

- COREQChecklistPostnatalcaretrajectoryanalysis.docx

- Additionalfile1.docx 